\title{
АКТУАЛЬНЫЕ ПРОБЛЕМЫ И ПЕРСПЕКТИВЫ ВНЕДРЕНИЯ АВТОМАТИЗИРОВАННЫХ ИНФОРМАЦИОННО-ПОИСКОВЫХ СИСТЕМ В ОПЕРАТИВНО-РОЗЫСКНУЮ И СЛЕДСТВЕННУЮ ДЕЯТЕЛЬНОСТЬ
}

\author{
Денисов Е.В.
}

Аннотация: В настоящуей статье изучается российский и зарубежный опыт исследования и внедрения в следственную и оперативно-розыскную практику автоматизированных информационно-поисковых систем (АИПС), предназначенных для построения психологических профилей неустановленных преступников, преимущественно совершивиих тяжкие и особо тяжкие преступления против личности, также предлагается авторская концепция общей архитектуры и функиионирования данных систем. Приводятся данные об эффективности работь АИПС, иелесообразности их применения по определённым категориям дел. Даётся теоретическое обоснование возможности построения психологического портрета преступника исходя из возможностей математической статистики и психоанализа. Метод или методология исследования: В процессе исследования были применены общценаучные методы анализа, синтеза и сравнения, а также функциональный метод и системный подход. Анализировались математические и психологические методы исследования информации о преступлении. Научная новизна и выводы: На основе отечественных и зарубежных источников проанализированы алгоритмы работы различных АИПС, дана оценка достоверности и надёжности предоставляемых ими данных. Исследована программная архитектура действующих зарубежных программных комплексов и аналогичных систем, разрабатываемых в России, на основании чего сделаны предложения по концепции функциионрования новой отечественной АИПС, предназначенной для построения психологических портретов, выявления признаков серийности между преступлениями и ведения учёта лиц из групп риска. Сделаны выводы об обоснованности профилирования тяжких и особо тяжких преступлений с точки зрения математической статистики и психоанализа.

Ключевые слова: Профилирование, географический профиль, аипс, modus operandi, криминалистическая характеристика, базы данных, анализ версий, информатизация расследования, признаки серийности, преступник.

Анализируя проблему раскрываемости преступлений за последние 3 года, можно констатировать, что нераскрытыми остаются 43-44\% от общей массы преступлений. Количество нераскрытых тяжких и особо тяжких преступлений колеблется на уровне $24 \%$, равно как и их процент от общего числа[1]. У этого явления несколько причин, одна из которых - подготовка квалифицированных ка- дров. В данном аспекте необходимо выделить два критерия: первый - качество образования в вузе и второй - опыт работы.

В части, касающейся первого критерия, можно сказать, что во многих регионах нет необходимой кадровой преподавательской базы для подготовки сотрудников правоохранительных органов. Большинство преподавателей региональных юридиче- 
ских вузов и их филиалов являются «выходцами» из системы МВД (для службы в которой не предусмотрено требования об обязательном высшем юридическом образовании даже в следственных подразделениях[2]), многие не имеют учёных степеней по юридическим наукам, не имея интереса к профессиональному росту, они теряют квалификацию. В результате некоторые следователи Следственного комитета и Федеральной службы безопасности Российской Федерации не имеют достаточного опыта в области ведения предварительного следствия, теории ОРД и юриспруденции; у значительного числа следователей территориальных органов СКР отсутствуют знания о методах сбора образцов для генотипического исследования, свойствах веществ (выделений), содержащих ДНК; подчас сотрудники не обладают навыками обнаружения, фиксации и изъятия следов пальцев рук и пониманием специфики их выявления на различных поверхностях.

Относительно второго критерия считаем нужным отметить, что по состоянию на 2010 г. (по нашим сведениям, изменения в показателе на данный момент не составляют более 5\%) опытными, т.е. имеющими стаж следственной работы в органах Прокуратуры - СКР более 5 лет, являются только около половины всех сотрудников[3], что не может позитивно влиять на качество предварительного следствия по линии Следственного комитета РФ. Ещё одной причиной является традиционно низкая техническая оснащённость территориальных экспертно-криминалистических подразделений, особенно в системе МВД, в которой, помимо прочего, отсутствует эффективный механизм обеспечения сотрудников методическими и учебно-методическими указаниями по криминалистике, методам выявления-фиксации-изъятия следов при осмотре места происшествия, производству традиционных и специальных экспертиз, ведению криминалистических учётов.

Отдельной проблемой в данном контексте является информационное обеспечение расследования преступлений. В этой связи следует обратить внимание на отсутствие единой и доступной для всех уполномоченных служб базы данных, в которую бы вносились сведения, количественный и качественный анализ которых мог бы способствовать выдвижению версий относительно направления расследования, снижая тем самым роль «человеческого фактора» и помогая сотрудникам правоохранительных органов ориентироваться в собираемом информационном массиве. Наиболее остро описанная проблема возникает при расследовании тяжких и особо тяжких преступлений против личности, в особенности серийных убийств и изнасилований, а ведь расследования именно данной категории дел обычно вызывают особую сложность.

В связи с вышеизложенным мы полагаем, что на сегодняшний день возникла необходимость создания единой для всех правоохранительных органов автоматизированной информационно-поисковой аналитической системы, содержащей сведения о преступлениях, их криминалистических характеристиках и включающей алгоритмы анализа обстоятельств этих преступлений. Данный комплекс позволит проводить идентификационные исследования способов совершения преступлений, выявлять признаки серийности между отдельными эпизодами и создавать психологический/географический профиль неустановленного преступника.

Дополнительную актуальность и обоснованность данной проблеме придают выдающиеся результаты в области подобной информатизации процесса расследования преступлений в США, Канаде, и некоторых странах ЕС, хотя в отечественной науке и практике эти достижения остаются малоизвестными. Так, в западных странах ещё с 1980-1990 гг. используются такие информационно-аналитические комплексы как INPOL, VICAP, CATCHEM, а также иные системы централизованного учёта и анализа обстоятельств и способа совершения преступления. Уместно сказать, что в России разработка аналогичных систем также велась, например, во ВНИИ МВД РФ была разработана АИПС «Монстр», призванная составлять психологические портреты преступников, однако по ряду причин она давала информацию весьма низкого качества, которая не могла в достаточной мере способствовать созданию поискового портрета личности злоумышленника по тем или иным психологическим и социально-демографическим признакам[4]. Так же отечественной наукой достаточно глубоко проработаны теоретические вопросы создания информационно-аналитической системы описываемого класса, обоснования эффективности использования данных криминалистических характеристик преступлений, статистических данных, отражающих корреляции способа совершения преступления, особенностей ориентации на местности, отношений с жертвой и прочих аспектов поведения преступника. Указанные разработки, а также близкие к ним по тематике изложены в трудах таких учёных как Густов Г. А., Великородный П. Г., Усанов И. В., Кустов А. М., Ищенко Е. П., Бондаренко Р. В., Колдин В. Я., 
Волчецкая Т. С., Видонов Л. Г., Селиванов Н. А., Фесик П. Ю., Анфиногенов А. И., Толстолуцкий В. Ю., Антонян Ю. М., Зуйков Г. Г. Отметим, что в данных изысканиях, по нашему мнению, не вполне учитывается зарубежный опыт, особенно в части внедрения информационноаналитических систем в широкую практику и применения перспективных психологических методов анализа поведения подозреваемого на месте происшествия, с целью их внесения в базу под определённой рубрикой анализа.

Обращаясь к зарубежному опыту, можно констатировать весьма существенное отставание российских правоохранительных органов в разработке и, особенно, в практическом применении автоматизированных информационно-поисковых систем. Также в правоохранительной системе не имеется информационных баз с равным доступом для всех органов, проводящих следственные и оперативно-розыскные мероприятия. В таких условиях крайне усложняется даже не проверка достоверности информации о серийности, а установление наличия сведений о проверяемом лице в криминалистических и специальных учётах. Совершенно по-другому складывается практика в США и Западной Европе. Например, в США Федеральное бюро расследований является оператором, а уполномоченные службы пользователями объединённой автоматизированной дактилоскопической информационной системы, содержащей 71,5 млн. дактилокарт по криминальным учётам[5], также ФБР имеет в своём распоряжении систему мгновенной проверки лиц, желающих приобрести огнестрельное оружие (NICS)[6] и уже упомянутую VICAP; во Франции в 1990 г. была принята программа полной компьютеризации МВД, включавшая создание обширных информационных сетей обмена данными, а в Великобритании в 1991 г. начал эксплуатироваться новый национальный вычислительный центр полиции (PNC-2)[7]. При этом необходимо отметить, что за рубежом также имеются весьма серьёзные недостатки в плане развития АИПС. Так, в Германии МВД испытывало существенные трудности при создании информационно-поисковой системы INPOL, связанные с несовершенством её архитектуры, а использование VICAP критикуется из-за нерепрезентативности статистических данных, подчас некачественно вводимых в электронные анкеты местными полицейскими службами[8].

Принцип действия перспективной АИПС для российских правоохранительных органов при её назначении, направленном на выявление признаков серийности между преступлениями и составление психологического и географического профиля, нам представляется состоящим из группы рубрик, содержащих признаки, характерные для определённых категорий преступлений, а также информацию по собранным в рамках расследования доказательствам. Помимо этого, в базе данных указанного программного комплекса должны храниться статистические данные о преступлениях определённых видов, анализ которых поможет определить общие наиболее вероятные характеристики обстоятельств происшествия и задействованных в нём лиц. К примеру, в используемой в Великобритании АИПС (САТСНЕМ) заложен алгоритм, учитывающий, что по общему правилу к перевозке или перемещению жертв более склонны субъекты в возрасте 30-35 лет, нежели от 18 до 25 лет. К тому же, статистические данные, являясь одновременно единой электронной картотекой способов совершения преступлений, могут быть задействованы для раскрытия преступлений прошлых лет, а также в научных целях, помогая устанавливать деградационные наклонности в поведении преступников в уже выявленных сериях и обнаруживать ещё не идентифицированные серии по имеющимся сходствам почерка.

Между АИПС, разработанными в целях профилирования в Северной Америке и Европе, и некоторыми апробируемыми разработками в России («ФОРВЕР», «Глухарь», «Монстр») имеется несколько значимых различий, которые необходимо учитывать при создании глобальной отечественной АИПС.

Западные системы, главным образом VICAP и САТCHЕМ, частично используют для анализа данных имеющиеся в них статистические корреляции выявленные в ранее совершённых преступлениях (к примеру, соотнесение мест обнаружения трупов и способа совершения преступления с вероятным районом проживания злоумышленника), так называемыми моделями[9], а также modus operandi[10] (далее - MO); аналогией этого термина в российской криминалистике может являться способ совершения преступления, так как его суть заключается именно в деятельности преступника при совершении преступления. Непосредственно из анализа данных МО указанные программы исходят при построении психологического и социально-демографического портрета преступника. Так, VICAP сравнивает в процессе обработки информации о преступлении более 100 МО и выбирает 10 наиболее близких вариантов, содержащих сходные с проверяемым преступлени- 
ем случаи. Таким образом, выявляются признаки серийности и определяется психологический портрет преступника по имеющимся в базе данным, а также анализу отображённых в следовой обстановке и пространственно-временных данных криминального события, психологических паттернов.

Перспективные российские АИПС, например, такие как «ФОРВЕР», оперируют данными криминалистических характеристик убийств на основе ранее рассмотренных уголовных дел[11]. В программе на основании методов математической статистики производится расчёт вероятности неизвестных признаков за счёт известных[12]. Схожий принцип используется в системе САТСНЕМ с применением Байесовских сетей, при помощи которых устанавливаются вероятностные отношения в преступлении[13]. Использование подобных алгоритмов, по нашему мнению, в большинстве случаев оправдано, однако, стоит заметить, что данному методу свойственны логические ошибки, выраженные в распространении какого-либо признака на слишком объёмную категорию лиц, «входящую» в профиль и усугубляющиеся отсутствием модуля анализа поведения преступника, действующего через анализ МО по конкретным особенностям преступлений. Иными словами, криминалистические характеристики анализируются слишком широко, поэтому результаты подобных статистических обобщений могут давать «осечки», а выборки способов совершения преступлений, как наиболее важной части криминалистической характеристики, не представлены в достаточной степени.

Заметим, что при изучении проблемы качества работы АИПС, построенных на статистических системах анализа, важно понимать различия между криминалистической характеристикой преступления и способом его совершения. Е. П. Ищенко в приводимой формулировке указывает: «криминалистическая характеристика - это система описания криминалистически значимых признаков вида или группы преступлений, проявляющихся в особенностях способа, механизма и обстановки совершения, личности виновного и иных обстоятельств конкретного преступного посягательства, существенных для его успешного раскрытия и расследования»[14]. Таким образом, способ и обстановка совершения преступления, являясь составными частями криминалистической характеристики, не должны рассматриваться в отрыве от неё. При этом, отображая, по нашему мнению, бо́льшую часть информации, необходимую для составления психологического и социаль- но-демографического профиля преступника, эти элементы криминалистической характеристики должны прорабатываться более глубоко в рамках алгоритмов работы АИПС.

Представляется также, что нельзя до конца посредством только лишь статистического анализа криминалистической характеристики в целом описать корреляции между, например, социальнодемографической характеристикой преступника и формами совершённого им сексуального насилия. Между тем, существуют базы, учитывающие и эти особенности: в них могут вноситься данные об особых приметах подозреваемого, способах насилия/убийства, месте и времени совершения преступлений, наличия попыток предварительного вербального контакта с потенциальной жертвой и их формы. Составление отдельных статистических выборок из МО оправдано ещё и тем фактом, что преступник в процессе совершенствования своего «мастерства» или в результате психологической деградации, изменения форм реакций на внешние раздражители в процессе течения психического заболевания может изменять почерк, что частично отображается именно в способе совершения преступления. К примеру, в науке достаточно хорошо известны «эскалации» грабителей-фетишистов до сексуальных убийц[15]. Конечно, в соответствии с психологической теорией отражения, почерк преступника не будет меняться полностью, но внешне с течением времени может предстать в достаточно деформированном виде. Именно поэтому мы считаем необходимым выделять способ совершения преступления как отдельный статистический раздел АИПС профилирования.

Основываясь на вышеизложенном, считаем необходимым в рамках данной работы привести своё видение архитектуры и системы функционирования перспективной АИПС для российских правоохранительных органов, которая могла бы использоваться для построения версий и создания психологических профилей по тяжким и особо тяжким преступлениям.

Указанная система должна сочетать в себе три модуля: анализа, учёта и взаимодействия с другими аналитическими системами и базами данных. Аналитический модуль необходим для основной работы системы - формирования версий и профилей. Модуль учёта в системе требуется для хранения информации о лицах, у которых обнаружены черты, свойственные преступникам, совершающим убийства на сексуальной почве, садистам, насильникам похитителям и т.п. Как вариант, в такую базу должны вноситься под- 
ростки, у которых отмечены такие наклонности из Триады Макдональда как пиромания и, в особенности, зоосадизм.

В системе должны также сочетаться связанные между собой автоматизированная информационноаналитическая и поисковая система, подключённая к компьютеризированным криминалистическим и специальным учётам МВД РФ, для оперативной проверки составленного системой профиля по прочим критериям с целью идентификации субъекта, совершившего преступление. Доступ к АИПС должны иметь все сотрудники заинтересованных ведомств, имеющие необходимый допуск и квалификацию, однако в отличие от VICAP, отечественный комплекс в части субъекта ввода данных должен быть федеральным; внесение в него данных территориальными правоохранительными органами должно контролироваться из центра управления, дабы исключить внесение ошибок в программный алгоритм статистического анализа.

Такой принцип действия позволит, во-первых, вести централизованный учёт данных о фактах и обстоятельствах совершённых тяжких и особо тяжких преступлений и оперативно проверять на причастность к совершению преступления выявленных лиц, устанавливать признаки серийности между преступлениями в масштабе всей страны, а во-вторых, автоматически составлять психолого-криминалистический и социально-демографический профиль неустановленного преступника. Примером может служить вывод о его поле, примерном возрасте (в пределах 5 лет), роде занятий, определённых заболеваниях, расе, привычках и т.п. Одновременно в функционал программного комплекса должны включаться картографические системы, необходимые для построения географического профиля субъекта в зависимости от мест совершаемых преступлений. Отметим, что корреляции между способом совершения преступления, поведением преступника и географической удалённостью мест преступления друг от друга и от места жительства субъекта выявлены ещё в 70-е годы XX века в США и в настоящее время подтверждены российскими криминалистами и криминологами[16].

Относительно потенциальной точности описываемой системы можем отметить, что по последним исследованиям, проводимым, в частности, В. Я. Колдиным, она должна будет составлять примерно 90,03 \% при достаточности данных[17], а для системы «ФОРВЕР» по некоторым параметрам до 95\%[18]. Таковыми данными для АИПС[19] могут являться: место преступления (с помощью кото- рого можно составить геопрофиль), время, способ совершения преступления и сокрытия его следов (характер повреждений, их локализация, орудие преступления), место «сброса» орудия убийства и его положение относительно места происшествия, поза трупа (если есть основания полагать, что он перемещался преступником).

Наряду с описанием характеристик АИПС, представляется важным упомянуть о возможности и целесообразности её использования для работы по неоднородным категориям дел. Необходимо отметить факт наличия расхождения во мнениях между российскими и американскими криминологами и криминалистами относительно возможности применения АИПС при построении профиля по определённым видам преступлений. Так, например, С. В. Милюков[20] и В. Я. Колдин [21] полагают, что методика профилирования, в том числе с использованием АИПС, применима как для особо тяжких преступлений против личности, так и при расследовании грабежей, разбоев и серийных краж. Напротив, В. А. Образцов считает, что данные методики применимы исключительно для преступлений, в которых в достаточной степени отражаются психологические (психопатические) наклонности субъекта. В данном вопросе, по нашему мнению, следует занимать промежуточную позицию, опираясь на устоявшиеся в криминалистике подходы к теории следообразования, в том числе в части формирования идеальных образов в сознании субъекта и их переноса на материальные объекты. Полагаем, что профилирование применимо в тех случаях, когда следовая обстановка преступления и пространственно-временные связи так или иначе отражают субъективные предпочтения лица относительно способа совершения преступления, поведения в процессе его подготовки, совершения и сокрытия его следов (если таковое имело место). Например, нам не представляется возможным построение профиля большинства преступников, совершающих квартирные кражи из-за разности обстановки в квартирах, корыстного мотива, как «сбивающего» фактора, и отсутствия жертвы и насилия над ней, как обязательного элемента профилируемого преступления. Невозможно достаточно точное отражение личности субъекта в следовой обстановке на месте происшествия, а следовательно, внесение данных в АИПС для эвристического анализа отображённых психологических паттернов. К тому же, полагаем, что расследование корыстных преступлений таким методом попросту нерационально с экономической и организационной точек зрения. 
Однако заметим, что в США метод профилирования и анализа криминального поведения применяется намного шире, нежели расследование исключительно серийных сексуальных убийств. Так, в структуре Национального центра анализа тяжких преступлений ФБР [22] присутствуют 4 отдела анализа поведения:

1-й отдел - контртерроризм, поджоги, ВУ;

2-й отдел - угрозы, киберпреступления, националисты, коррупция;

3-й отдел - преступления против детей;

4-й отдел - преступления против взрослых.

Также имеется отдельное подразделение, решающее исследовательские и методические вопросы.

Описав некоторые вопросы преимущественно инструментальных способов построения психолого-криминалистических и социально-демографических портретов неустановленных преступников, считаем, что для более полного понимания их методики, применяемой в западных странах, необходимо также кратко отразить в данной работе уровень научных достижений в области неинструментальных исследований, так как именно они послужили научной и практической основой для создания АИПС профилирования.

Неинструментальный (ментальный) способ анализа поведения и построения психологического портрета (профиля) во многом повторяет принцип работы инструментальной системы. Основное различие заключается в алгоритмическом изучении аналитиком данных, полученных в результате ОМП. Такой алгоритм, по мнению сотрудников ФБР, должен выглядеть следующим образом:

- обстоятельное изучение, анализ природы и сущности преступления и криминальных типов лиц (психолого-психиатрическая типология), совершивших подобные деяния в прошлом;

- исчерпывающий анализ места расследуемого преступления;

- углубленное изучение ближайшего окружения, рода занятий и увлечений жертвы (жертв) и подозреваемого;

- формирование всех возможных мотивирующих факторов всех задействованных в расследовании лиц;

- $\quad$ описание преступника (на основе внешних поведенческих проявлений его вероятной психологической сущности) [23].

Главный постулат, на котором базируется теоретическое обоснование неинструментального профилирования, сводится к тезису о том, что поведение преступника на месте преступления в определённых условиях склонно к некоему автоматизму, контролируемому сферой бессознательного, впервые в должной мере описанной К. Г. Юнгом и другими неофрейдистами. Именно к сфере бессознательного, изучаемой посредством научного инструментария психоанализа, может относиться способ действий преступника в процессе совершения преступления (особенно сексуальных убийств). Например, субъект, заразившийся гепатитом в результате полового контакта, вырезал жертвам (женщинам) печень. Несомненно, данное действие не может в полной мере контролироваться сознанием и поэтому продуцируется из бессознательной сферы, приобретая также компульсивный характер. Одновременно, действия преступника отражают его личностные особенности, будь то привычки, по которым можно сделать вывод о его деятельности, формы сексуального насилия, позволяющие дать заключение о поведении субъекта в быту или протекании у него неких психических заболеваний или выбор жертв, который может дать информацию обо всём из вышеперечисленного. Таким образом, малоконтролируемое поведение преступника (особенно в случае с сексуальными убийцами) в совокупности с неизбежным отражением на месте происшествия его бессознательных/ архетипических мотивов обеспечивает возможность математического и психоаналитического анализа обстоятельств его преступлений и построения психологического портрета. Ещё один интересный вывод, который можно сделать из изучения методик профилирования заключается в том, что совершенно разные люди, совершая преступления, действуют по схожим психологическим паттернам, поддающимся классификации, при этом исключения из таких моделей бывают крайне редки. Этот факт подтверждают данные об общности видов психических аномалий серийных убийц, а также то, что в процессе совершения преступлений они реализуют некую «программу», перекликающуюся с архетипами К. Г. Юнга; ведь только этим объяснимо, почему в целые группы можно объединить насильников по признаку того, что они специально снимают с жертв только один (!) ботинок или что многие маньяки стремятся вонзить в тела жертв какие-либо предметы типа палок или бутылок.

Подытожив вышесказанное, можем сделать вывод, что в отечественной науке существует достаточная теоретическая и практическая основа для создания и развития автоматизированных информационно-поисковых систем, которые могут оказать существенную помощь правоохранитель- 
ным органам в оптимизации методов изучения и борьбы с преступностью, а также ведении централизованного учёта тяжких и особо тяжких преступлений. При таком условии, создание указанной системы, не приводя к большим затратам, будет способствовать своевременному выявлению и задержанию опасных преступников, предотвращению совершения новых преступлений, что не замедлит положительно сказаться на экономических и социальных показателях жизни страны.

\section{Библиография:}

1. Ищенко Е. П. «Реформой правит криминал?». - М.: Юрлитинформ, 2013.

2. Ищенко Е. П. Криминалистика: Курс лекций. - М.: АСТ-МОСКВА, 2007.

3. Усанов И. В. Распознавание серийного характера убийств, совершённых сходными способами: Учебно-методическое пособие. - М.: Юрлитинформ, 2010.

4. Каримов В. Х. Автоматизированные информационно-поисковые системы криминалистического назначения: современное состояние, тенденции и перспективы развития. - М.: Юрлитинформ, 2014.

5. James Alan Fox, Jack Levin (1998). Multiple Homicide: Patterns of Serial and Mass Murder. Crime and Justice, Vol. 23.

6. Wayne Petherick (2014). Profiling and Serial Crime. Theoretical and Practical Issues. Third Edition. Elsevier Inc.

7. Фесик П. Ю. Технология использования криминалистической характеристики в раскрытии убийств: дисс. ... канд. юрид. наук. Н. Новгород, 2012.

8. D. Kim Rossmo (2000). Geographic profiling. CRC Press LLC.

9. Andrew E. Brankley, Alasdair M. Goodwill, Kylie S. Reale (2013). Escalation from Fetish Burglaries to Sexual Violence: A Retrospective Case Study of Former Col., D. Russell Williams. Journal of Investigative Psychology and Offender Profiling.

10. Метелев А. В. Использование специальных психологических знаний при раскрытии серийных убийств. Ижевск, 2009.

11. Колдин В. Я. Версионный анализ. - М.: Юрлитинформ, 2014.

12. Милюков С. В. Современные возможности использования свойств человека при установлении личности в раскрытии и расследовании преступлений. - М.: Юрлитинформ, 2013.

\section{References (transliterated):}

1. Ishchenko E. P. «Reformoi pravit kriminal?». - M.: Yurlitinform, 2013.

2. Ishchenko E. P. Kriminalistika: Kurs lektsii. - M.: AST-MOSKVA, 2007.

3. Usanov I. V. Raspoznavanie seriinogo kharaktera ubiistv, sovershennykh skhodnymi sposobami: Uchebnometodicheskoe posobie. - M.: Yurlitinform, 2010.

4. Karimov V. Kh. Avtomatizirovannye informatsionno-poiskovye sistemy kriminalisticheskogo naznacheniya: sovremennoe sostoyanie, tendentsii i perspektivy razvitiya. - M.: Yurlitinform, 2014.

5. James Alan Fox, Jack Levin (1998). Multiple Homicide: Patterns of Serial and Mass Murder. Crime and Justice, Vol. 23.

6. Wayne Petherick (2014). Profiling and Serial Crime. Theoretical and Practical Issues. Third Edition. Elsevier Inc.

7. Fesik P. Yu. Tekhnologiya ispol'zovaniya kriminalisticheskoi kharakteristiki v raskrytii ubiistv: diss. ... kand. yurid. nauk. N. Novgorod, 2012.

8. D. Kim Rossmo (2000). Geographic profiling. CRC Press LLC.

9. Andrew E. Brankley, Alasdair M. Goodwill, Kylie S. Reale (2013). Escalation from Fetish Burglaries to Sexual Violence: A Retrospective Case Study of Former Col., D. Russell Williams. Journal of Investigative Psychology and Offender Profiling.

10. Metelev A. V. Ispol'zovanie spetsial'nykh psikhologicheskikh znanii pri raskrytii seriinykh ubiistv. Izhevsk, 2009.

11. Koldin V. Ya. Versionnyi analiz. - M.: Yurlitinform, 2014.

12. Milyukov S. V. Sovremennye vozmozhnosti ispol'zovaniya svoistv cheloveka pri ustanovlenii lichnosti v raskrytii i rassledovanii prestuplenii. - M.: Yurlitinform, 2013. 